\title{
molecules
}

ISSN 1420-3049

http://www.mdpi.org

Full Paper

\section{Oxidative Degradations of the Side Chain of Unsaturated Ent-labdanes. Part I.}

\author{
Luis Espinoza Catalán ${ }^{1, *}$, Héctor Carrasco Altamirano ${ }^{2}$, Mauricio Cuellar Fritis ${ }^{3}$, Claudio \\ Gallardo Araya ${ }^{1}$ and Karen Catalán Marín ${ }^{1}$ \\ ${ }^{1}$ Departamento de Química, Universidad Técnica Federico Santa María, Av. España № 1680, \\ Valparaíso, Chile \\ 2 Departamento de Ciencias Químicas, Universidad Andrés Bello, Campus Viña del Mar, Los Fresnos \\ $\mathrm{N}^{\circ}$ 52, Viña del Mar, Chile \\ ${ }^{3}$ Facultad de Farmacia, Universidad de Valparaíso, Av. Gran Bretaña № 1093, Valparaíso, Chile
}

* Author to whom correspondence should be addressed; E-mail: luis.espinozac@usm.cl

Received: 22 November 2006; in revised form: 19 January 2007 / Accepted: 24 January 2007 /

Published: 6 March 2007

\begin{abstract}
A selective route for the degradation of the unsaturated side chain of ent-labdanes has been devised, giving two useful synthons: $2 \beta$-acetoxy-14,15,17-trinor-ent-labdane-8,13dione (5) and $2 \beta$-acetoxy-14,15-dinor-ent-labd-8(17)-en-13-one (7), the use of which for the preparation of terpenylquinone derivatives shall be reported elsewhere.
\end{abstract}

Keywords: Ent-labdanes, selective degradations, unsaturated side chain.

\section{Introduction}

Diterpenoids with labdanic structures are a very important natural source of hydrocarbon skeletons which have been used in the elaboration of a great number of drimane compounds with remarkable biological properties, among which their olfactory [1-3], antifeedant [4], antimicrobial, cytotoxic [5], growth regulator [6], herbicidal and insecticidal activities [7-10] may be mentioned.

The more common templates used for semisynthetic work are tricyclic diterpenoids such as (+)-abietic acid, (-)-levopimaric acid, podocarpic acid and bicyclic diterpenoids like manool, the communic acids, (-)-sclareol, (+)-cis-abienol, labdanolic acid, glycirretinic acid [11] and zamoranic acid [12-13]. Oxidative cleavage reactions of the side chain of communic acids with ozone and the 
$\mathrm{OsO}_{4}-\mathrm{NaIO}_{4}$ system have been reported previously [14]. The synthesis of sesquiterpenoids from labdane diterpenoids has also been reported [15]. On the other hand, degradations in the side chain of dihydrozamoranic acid were used for the synthesis of drimane [16]. Another important group of chemical reactions which included degradations in the side chain of (-)-sclareol, are those that allowed the preparation of terpenic synthons used in the synthesis of terpenylquinones with antitumoral activities such as $(+)$-puupehenone [17], chromazonarol and related compounds [18]. A new series of antineoplastic diterpenylquinone/hydroquinones has been prepared by using another route involving Diels-Alder cycloadditions between three labdanic diterpenoids (myrceocommunic acid derivatives) and $p$-benzoquinone or 1,4-naphthoquinone [19].

In this report we present our results on oxidative degradations of the side chain of natural entlabdanes isolated from Calceolaria inamoena. Plants of the genus Calceolaria (Scrophulariaceae) are found distributed throughout New Zealand, Central and South America, including Chile, where there are 85 species (C. inamoena is a shrub common in the northern subandean region of Arica, Region I, Chile) [20].

\section{Scheme 1.}
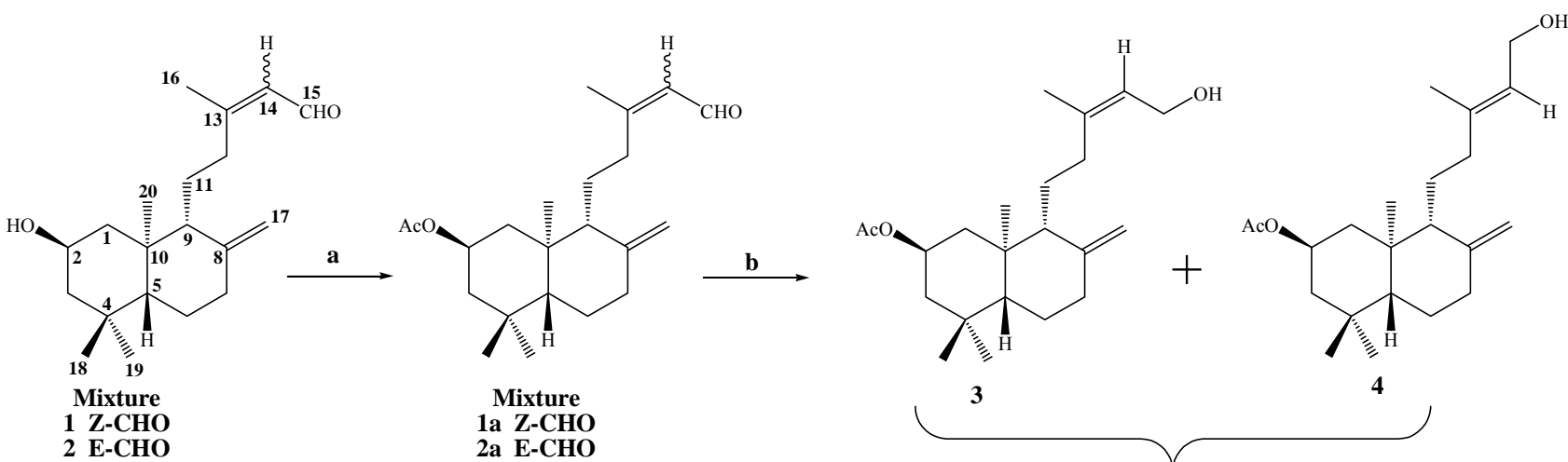

Mixture

2a E-CHO

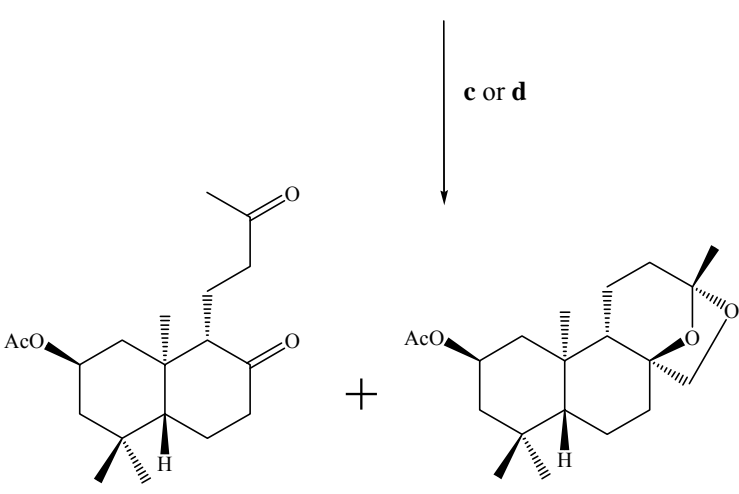

5

6

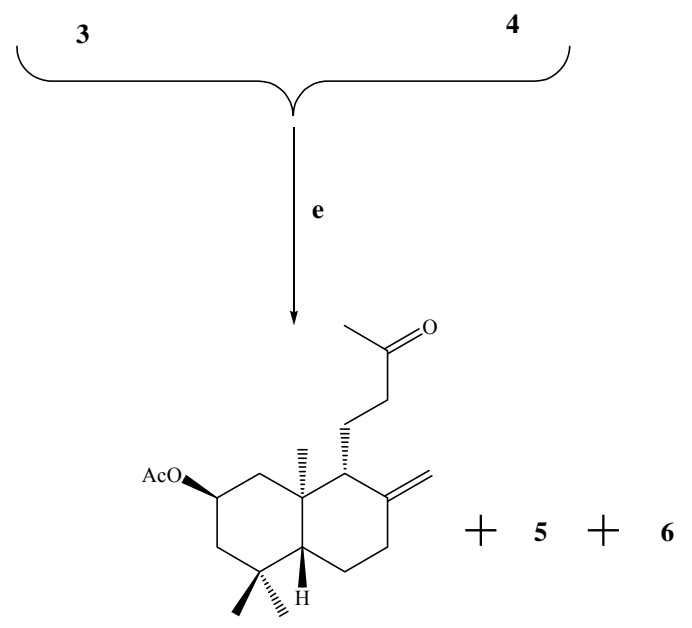

7

Conditions: a. $\mathrm{Ac}_{2} \mathrm{O} / \mathrm{CH}_{2} \mathrm{Cl}_{2}$ /py, DMAP, r.t, 2 h, $98 \%$; b. $\mathrm{NaBH}_{4}, \mathrm{MeOH}, 10^{\circ} \mathrm{C}, 1.8$ h, 3, 28\%, 4, $43 \%$ and 3+4, 29\%; c. $\mathrm{OsO}_{4} / \mathrm{NaIO}_{4}$, THF/H $\mathrm{H}_{2} \mathrm{O}(1: 1)$, r.t, 72 h, 5, 68\%, 6, 7.2\%; d. $\mathrm{RuCl}_{3} \cdot 3 \mathrm{H}_{2} \mathrm{O}$, $\mathrm{MeCN} / \mathrm{H}_{2} \mathrm{O}, \mathrm{NaIO}_{4}, 40^{\circ} \mathrm{C}, 5$ h, 5, 76\%, 6, 6.3\%; e. $\mathrm{KMnO}_{4} / \mathrm{MgSO}_{4}, \mathrm{Me}_{2} \mathrm{CO}$, r.t, 72 h, 7, 63\%, 5, $8.6 \%$ and $6,1.2 \%$.

\section{Results and Discussion}

Our main goal in the oxidative degradation of the ent-labdane side chains was to obtain compounds 5 and 7 (Scheme 1), and use these to generate a primary alcohol at the C-12 position. This primary 
alcohol would then be transformed into a good leaving group, which in turn would lead to suitable terpenic fragments that could be reacted with quinone/hydroquinone moieties in an attempt to synthesize terpenylquinones/hydroquinones with potential anticancerogenic activities. The preparation of the primary alcohols and the synthesis of the terpenylquinones/hydroquinones will be reported elsewhere.

The structural determination of the mixture of compounds 1-2 was accomplished by ${ }^{1} \mathrm{H}-$ and ${ }^{13} \mathrm{C}$ NMR techniques. The spectral data, when compared with those previously reported for compounds with similar structures containing ent-labdane skeletons [21, 22], were consistent with a diterpenic bicyclic labdane structure having a $\Delta^{8(17)}$ double bond and a $2 \beta$-hydroxyl group. Examination of the ${ }^{13} \mathrm{C}-\mathrm{NMR}$ spectra of acetylated derivates 1a-2a, showed that they were a 60/40 mixture of the C-13 E and $Z$ isomers, respectively. After successive purifications of 1a-2a by column chromatography (C.C.) a 10:1 E:Z mixture was isolated (ratio calculated based on the integrals of the Me-16 signals in the ${ }^{1} \mathrm{H}-$ NMR spectrum). This mixture was used for the structural determination of compound $1 \mathrm{a}$, whose ${ }^{1} \mathrm{H}$ NMR spectrum indicated the existence of a hydrogen at $\delta 9.96(1 \mathrm{H}, \mathrm{d}, J=8.1 \mathrm{~Hz}, \mathrm{H}-15)$ corresponding to an aldehyde function, three singlet methyl groups at $\delta 0.75,0.86$ and $0.91 \mathrm{ppm}$ corresponding to Me-18, Me-19 and Me-20, respectively, as well as two broad singlets at $\delta 4.49$ and 4.87 ppm for the geminal H-17 vinylic protons. A double double triplet at $\delta 4.99 \mathrm{ppm}$ was also assignable to the hydrogen geminal to an acetyl group $\left(\underline{\mathrm{C}}_{3} \mathrm{CO} \delta 2.00 \mathrm{ppm}\right)$, and with the aid of a gs-sel- ${ }^{1} \mathrm{H}$ 1D TOCSY experiment, it was unequivocally determined to be located between $\mathrm{C}-1$ and C-3. No NOE cross peak was observed between H-5 and Me-20, which suggested that the latter is oriented trans to H-5. The relative stereochemistry of 1a was assigned on the basis of both a NOESY correlation and coupling constant data. Main NOESY correlations observed for 1a are shown in Figure 1, which indicated that ring $\mathbf{A}$ and $\mathbf{B}$ were trans-fused and $\mathrm{H}-2$ was axially oriented. On the other hand, an axial-axial $\left(J_{a a}=11.8 \mathrm{~Hz}\right)$ and axial-equatorial $\left(J_{a e}=4.2 \mathrm{~Hz}\right)$ coupling constant for H-1, H-2 $\alpha$ and H-3 indicated that the OAc group in $\mathrm{C}$-2 was $\beta$-equatorial (see Figure 1a). Furthermore, an allylic methyl group, as indicated by a signal in the ${ }^{1} \mathrm{H}-\mathrm{NMR}$ spectrum at $\delta 2.16 \mathrm{ppm}(\mathrm{C}-16, \delta 17.6 \mathrm{ppm})$, and long range coupled to a broad singlet corresponding to a vinylic proton at $\delta 5.86 \mathrm{ppm}$ (see Figure 1b) were characteristic of an unsaturated side chain of a bicyclic diterpenoid having an $E$ configuration at the olefinic bond [23]. Nevertheless, since our plans called for the loss of isomeric relationships at C-13, the 1-2 mixture was used directly as our synthesis.

Figure 1 Structure of compound 1a. (a) NOE correlations. (b) HMBC correlations.

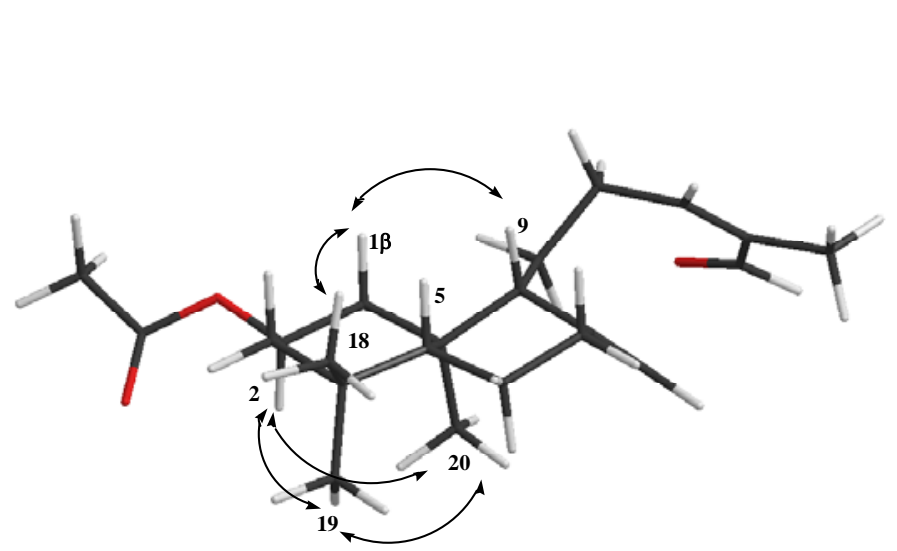

(a)

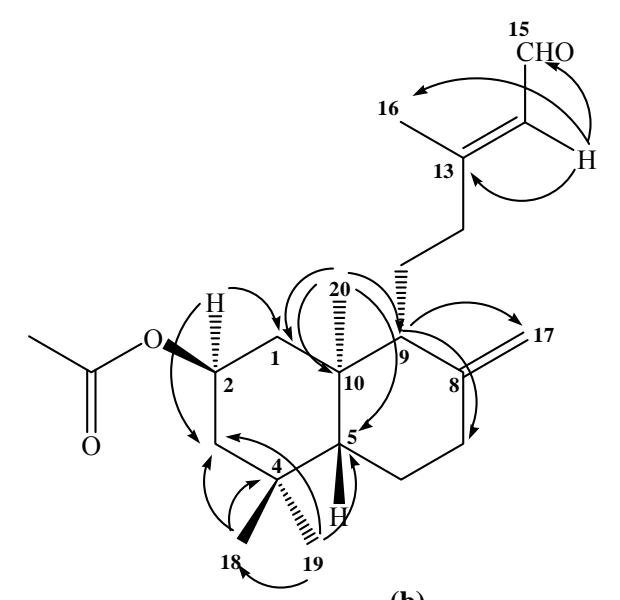

(b) 
Acetylation of the 1-2 mixture under standard conditions $\left(\mathrm{Ac}_{2} \mathrm{O} /\right.$ pyridine/ $\left.\mathrm{DMAP} / \mathrm{CH}_{2} \mathrm{Cl}_{2}\right)$ produced the acetate mixture 1a-2a in 98\% yield. Reduction of this acetate mixture with $\mathrm{NaBH}_{4} / \mathrm{CH}_{3} \mathrm{OH}$ after C.C. purification led to the formation of the geometrical isomers $3(28 \%)$ and 4 (43\%). The confirmation of the $E$ and $Z$ structures of these geometrically isomeric alcohols, was made by ${ }^{1} \mathrm{H}$ - and ${ }^{13} \mathrm{C}-\mathrm{NMR}$ data; specifically the $E$ isomer 4 showed a carbinol methylene group at $\delta=4.13$ $(2 \mathrm{H}, \mathrm{d}, J=6.9 \mathrm{~Hz}, \mathrm{H}-15)$ and a signal at $\delta=59.3(\mathrm{C}-15)$ in its ${ }^{13} \mathrm{C}$ spectrum, whereas the $Z$ isomer 3 showed a carbinol methylene group at $\delta=4.02(2 \mathrm{H}, \mathrm{dd}, J=6.9$ and $4.2 \mathrm{~Hz}, \mathrm{H}-15)$ and a ${ }^{13} \mathrm{C}$ signal at $\delta=$ 58.9 (C-15). A singlet peak at $\delta=1.65(3 \mathrm{H}, s, \mathrm{H}-16)$ and $\delta=16.3$ (C-16) indicated that the stereochemistry of the double bond in the side chain corresponded to $E$. In the case of the $Z$ isomer, the Me-16 appears at $\delta_{\mathrm{H}}=1.70$ and $\delta_{\mathrm{C}}=23.3 \mathrm{ppm}$, respectively.

Degradation of the side chain of the mixture of compounds 1a-2a using either the $\mathrm{OsO}_{4} / \mathrm{NaIO}_{4}$ or $\mathrm{RuCl}_{3} / \mathrm{NaIO}_{4}$ systems, a degradation used previously for compounds with similar structures [1-3, 14], led to the formation of compounds 5 and $\mathbf{6}$ (Scheme 1). Nevertheless, when the mixture 1a-2a was treated with the $\mathrm{RuCl}_{3} / \mathrm{NaIO}_{4}$ system, a greater yield of compound 5 was obtained $(76 \% \mathrm{v} / \mathrm{s} 68 \%$ with $\mathrm{OsO}_{4} / \mathrm{NaIO}_{4}$ system). The main spectroscopic data for the confirmation of the structure of 5 was the appearance of a singlet signal at $\delta_{\mathrm{H}}=2.05(3 \mathrm{H}, \mathrm{s}, \mathrm{H}-16)$ and $\delta_{\mathrm{C}}=29.8(\mathrm{C}-16)$; in addition, in its ${ }^{13} \mathrm{C}$ spectrum, the presence of two ketone carbonyl signals was observed at $\delta_{\mathrm{C}}=211.3$ (C-8) and 208.9 (C13). The molecular formula for compound $6\left(\mathrm{C}_{20} \mathrm{H}_{32} \mathrm{O}_{4}\right)$ was deduced from the combined spectra of ${ }^{1} \mathrm{H}$, ${ }^{13} \mathrm{C},{ }^{13} \mathrm{C}$-DEPT-135 and confirmed by MS $\left(\left[\mathrm{M}^{+} 336\right]\right.$ at $\left.\mathrm{m} / \mathrm{z}\right)$.

Our calculation of the degree of unsaturation gave a value of five, of which one corresponds to the acetate group, and two are attributed to the $\mathrm{A}$ and $\mathrm{B}$ rings. In the ${ }^{13} \mathrm{C}$ spectrum, no signals corresponding to $\mathrm{C}=\mathrm{C}$ double bonds were observed, therefore the formation of a third ring $\mathrm{C}$ fused with $\mathrm{B}$, formed by the union between the carbons C-8, C-9, C-11, C-12, C-13-O-C-8, and a fourth ring $\mathrm{D}$ fused with $\mathrm{C}$, formed by an ether bridge between $\mathrm{C}-13$ (ketal) and $\mathrm{C}-17$ is suggested.

The tetracyclic structure of compound $\mathbf{6}$ was confirmed mainly by the data obtained from heteronuclear 2D HSQC and HMBC correlations; in the latter, correlations were observed between H-17 $\beta$ with C-7, C-8 and C-9, whereas H-17 $\alpha$ shows correlations with C-9 and C-13, while the Me-16 group also showed correlations with $\mathrm{C}-13$ and $\mathrm{C}-12$ (see Figure 2a). The stereochemistry assigned to the carbons $\mathrm{C}-8$ and $\mathrm{C}-13$ were deduced from ${ }^{1} \mathrm{H}$ sel. 1D NOESY correlations; long range interactions between the Me-16 group with $\mathrm{H}-12 \beta$ and $\mathrm{H}-17 \beta$ were observed, whereas $\mathrm{H}-17 \alpha$ showed correlations with Me-20 and H-11 $\alpha$ (see Figure $2 b$ ). Finally, a tetracyclic structure similar to 6 was reported when labdadienes were treated with $\mathrm{O}_{3}$ or $\mathrm{NaIO}_{4} / \mathrm{OsO}_{4}$ system [14].

It is reported that allylic alcohols like (-)-sclareol or lab-13-en-8 $\beta$-ol-15-oic acid ( $\alpha, \beta$-unsaturated methyl esters) were selectively oxidized to the corresponding methyl ketones with the $\mathrm{KMnO}_{4} / \mathrm{MgSO}_{4}$ in acetone system $[24,25]$. Under these conditions, when compounds $\mathbf{3}, \mathbf{4}$ or a mixture of both were treated with $\mathrm{KMnO}_{4} / \mathrm{MgSO}_{4}$ in acetone at room temperature, compound 7 was obtained selectively in $63 \%$ yield. Specifically, in the ${ }^{1} \mathrm{H}-\mathrm{NMR}$ spectrum of 7 , the Me-16 appears at $\delta_{\mathrm{H}}=2.03(\mathrm{~s}, 3 \mathrm{H})$, whereas in the ${ }^{13} \mathrm{C}$ spectrum, the $\mathrm{CH}_{3}-\mathrm{CO}$ group showed signals at $\delta_{\mathrm{C}}=29.9(\mathrm{C}-16)$ and $208.8 \mathrm{ppm}(\mathrm{C}$ 13). On the other hand, the exocyclic double bond between $\mathrm{C}-8$ and $\mathrm{C}-17$ showed a signal at $\delta_{\mathrm{H}}=4.79$ $(1 \mathrm{H}, b s, \mathrm{H}-17 \mathrm{a})$ and $\delta_{\mathrm{H}}=4.40(1 \mathrm{H}, b s, \mathrm{H}-17 \mathrm{~b}), \delta_{\mathrm{C}}=147.0(\mathrm{C}-8)$ and $107.2(\mathrm{C}-17)$. Combined, all these signals confirm the structure of compound 7 and with it, the selectivity of the side chain oxidation reaction using $\mathrm{KMnO}_{4}$. 
Figure 2 Structure of compound 6. (a) HMBC correlations. (b) NOE correlations.

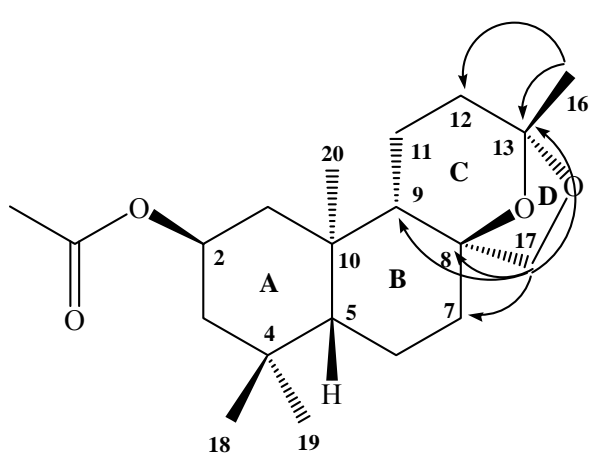

(a)

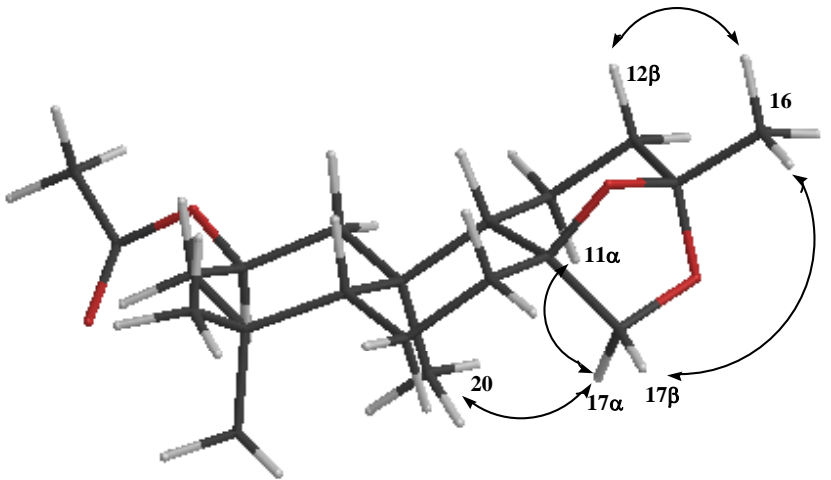

(b)

\section{Experimental}

\section{General}

Unless otherwise stated, all chemical reagents purchased (Merck or Aldrich) were the highest purity commercially available and were used without previous purification. IR spectra were recorded as thin films in a Nicolet Impact 420 spectrometer and frequencies are reported in $\mathrm{cm}^{-1}$. Optical rotations were measured with a sodium lamp ( $\lambda=589 \mathrm{~nm}$, D line) on a Perkin Elmer 241 digital polarimeter equipped with $1 \mathrm{dm}$ cells at the temperature indicated in each case. Low resolution mass spectra were recorded on a Shimadzu QP-2000 spectrometer at $70 \mathrm{eV}$ ionising voltage and are given as $\mathrm{m} / \mathrm{z}$ (\% rel. int.) ${ }^{1} \mathrm{H}-,{ }^{13} \mathrm{C}-$ (DEPT 135 and DEPT 90), sel. 1D ${ }^{1} \mathrm{H}$ NOESY, sel. 1D ${ }^{1} \mathrm{H}$ TOCSY, 2D HSQC and 2D HMBC spectra were recorded in $\mathrm{CDCl}_{3}$ solutions and are referenced to the residual peaks of $\mathrm{CHCl}_{3}$ at $\delta 7.26 \mathrm{ppm}$ and $\delta 77.0 \mathrm{ppm}$ for ${ }^{1} \mathrm{H}$ - and ${ }^{13} \mathrm{C}$-, respectively, on a Bruker Avance 400 Digital NMR spectrometer, operating at $400.1 \mathrm{MHz}$ for ${ }^{1} \mathrm{H}$ and $100.6 \mathrm{MHz}$ for ${ }^{13} \mathrm{C}$. Chemical shifts are reported in $\delta \mathrm{ppm}$ and coupling constants $(J)$ are given in Hz. Silica gel (Merck 200-300 mesh) was used for C.C. and silica gel plates HF-254 for TLC. TLC spots were detected by heating after spraying with $25 \% \mathrm{H}_{2} \mathrm{SO}_{4}$ in $\mathrm{H}_{2} \mathrm{O}$.

\section{Plant material}

Aerial parts of Calceolaria inamoena Phil. were collected in Arica, Region I, Chile, in January 2006, and authenticated by Professor Eliana Belmonte, Universidad de Tarapacá. A voucher specimen (\#98007) was deposited in the Herbarium of the Natural Product Laboratory of the Universidad Técnica Federico Santa María.

\section{Extraction and isolation}

Aerial parts of C. inamoena, (2,448 $\mathrm{g}$ of dry plant material) were successively extracted at room temperature with three $6.5 \mathrm{~L}$ portions of petroleum ether (b.p. $60-80^{\circ} \mathrm{C}$ ) for $72 \mathrm{~h}$ each. The solvent was removed in vacuo to yield $110.28 \mathrm{~g}$ of a syrupy residue. The crude material was divided into two portions (approx. $55 \mathrm{~g}$ each), dissolved in $\mathrm{CH}_{2} \mathrm{Cl}_{2}$ and absorbed on silica. Both portions were then each 
subjected separately to silica gel column chromatography $(450 \mathrm{~g})$ eluting with mixtures of petroleum ether and EtOAc of increasing polarity $(195: 5 \rightarrow 50: 150)$. Fractions (47 frs., $10 \mathrm{~mL}$, from a total of 248) were combined based on TLC and ${ }^{1} \mathrm{H}-\mathrm{NMR}$ monitoring. After purification by C.C. this produced 53.7 $\mathrm{g}$ of the geometric isomer mixture 1-2 (4.5\% yield based on dry plant material).

Acetylation of a mixture of 1-2: synthesis of 2 $\beta$-acetoxy-ent-labda-8(17),13(E)-dien-15-al (1a) and $2 \beta$ acetoxy-ent-labda-8(17),13(Z)-dien-15-al (2a).

To a solution of 1-2 mixture $(30 \mathrm{~g}, 98.5 \mathrm{mmol})$ in dry $\mathrm{CH}_{2} \mathrm{Cl}_{2}(150 \mathrm{~mL})$, dry pyridine $(10 \mathrm{~mL})$, DMAP (70 mg) and $\mathrm{Ac}_{2} \mathrm{O}(9.5 \mathrm{~mL})$ were added and the mixture was stirred at room temperature for 2 h. To this mixture a cooled solution of $10 \% \mathrm{KHSO}_{4}$ (approx. $25 \mathrm{~mL}$ ) was then added. The watery layer was discarded and the combined organic layers were washed to neutrality with a saturated solution of $\mathrm{NaHCO}_{3}$ and water, dried over $\mathrm{Na}_{2} \mathrm{SO}_{4}$, filtered, evaporated and chromatographed on silica-gel with petroleum ether/EtOAc mixtures of increasing polarity $(19.8: 0.2 \rightarrow 5: 15)$ to give a mixture of 1a-2a (33.4 g, 98\%). Compound 1a: viscous oil, ${ }^{1} \mathrm{H}-\mathrm{NMR}: 9.96(1 \mathrm{H}, \mathrm{d}, J=8.1 \mathrm{~Hz}, \mathrm{H}-15), 5.86(1 \mathrm{H}, \mathrm{d}$, $J=8.1 \mathrm{~Hz}, \mathrm{H}-14), 4.99$ (1H, ddt, $J=12.0,11.8$ and $4.2 \mathrm{~Hz}, \mathrm{H}-2), 4.87(1 \mathrm{H}, \mathrm{br}, \mathrm{H}-17 \mathrm{~b}), 4.49$ (1H, bs, H17a), 2.16 (3H, s, Me-16), 2.00 (3H, s, OAc), 0.91 (3H, s, Me-18), 0.86 (3H, s, Me-19), 0.75 (3H, s, Me-20); ${ }^{13} \mathrm{C}-\mathrm{NMR}: 44.0$ (C-1), 69.1 (C-2), 46.7 (C-3), 34.9 (C-4), 54.8 (C-5), 23.8 (C-6), 37.8 (C-7), 146.9 (C-8), 56.0 (C-9), 40.9 (C-10), 21.5 (C-11), 39.3 (C-12), 164.5 (C-13), 127.2 (C-14), 191.3 (C15), 17.6 (C-16), 107.4 (C-17), 33.4 (C-18), 22.3 (C-19), 15.2 (C-20), $170.6\left(\mathrm{CH}_{3} \underline{\mathrm{CO}}\right), 21.4$ ( $\left.\underline{\mathrm{C}}{ }_{3} \mathrm{CO}\right)$; IR: 2900-2980, 2850, 1720, 1640, 1460, 1395, 1360, 1250, 1140, 1020, 960, 895; MS: $346\left(\left[\mathrm{M}^{+}\right]\right.$ $<1 \%), 289$ (2.0\%), 286 (5.3\%), 203 (15.1\%), 201 (10.5\%), 189 (16.9\%), 187 (15.7\%), 175 (10.2\%), 159 (20.3\%), 157 (11.1\%), 149 (11.7\%), 147 (30.3\%), 145 (23.8\%), $136(14.2 \%), 135(100 \%), 133$ (34.0\%) 121 (30.7\%). Compound 1b: ${ }^{13} \mathrm{C}-\mathrm{NMR}: 43.9$ (C-1), 69.3 (C-2), 46.7 (C-3), 34.9 (C-4), 54.9 (C-5), 23.8 (C-6), 37.9 (C-7), 146.9 (C-8), 55.6 (C-9), 40.8 (C-10), 21.4 (C-11), 30.9 (C-12), 164.5 (C13), 129.0 (C-14), 190.9 (C-15), 24.8 (C-16), 107.6 (C-17), 33.5 (C-18), 22.3 (C-19), 15.1 (C-20), $170.6\left(\mathrm{CH}_{3} \underline{\mathrm{CO}}\right), 21.4\left(\underline{\mathrm{CH}}_{3} \mathrm{CO}\right)$.

Reduction of the mixture of 1a-2a: synthesis of 2 $\beta$-acetoxy-15-hydroxy-ent-labda-8(17),13(Z)-diene (3) and $2 \beta$-acetoxy-15-hydroxy-ent-labda-8(17),13(E)-diene (4)

$\mathrm{NaBH}_{4}(10.1 \mathrm{~g}, 0.266 \mathrm{~mol})$ was added in portions to a solution of 1a-2a mixture (10 g, $\left.28.9 \mathrm{mmol}\right)$ in $\mathrm{MeOH}(100 \mathrm{~mL})$, and the mixture stirred at $10^{\circ} \mathrm{C}$. After $2 \mathrm{~h}$, and in order to destroy the excess of $\mathrm{NaBH}_{4}$, acetone $(20 \mathrm{~mL})$ was added and the mixture stirred at room temperature for $15 \mathrm{~min}$. The solvent was removed until a volume of approximately $10 \mathrm{~mL}$ was reached and $\mathrm{HCl}(5 \%, 30 \mathrm{~mL})$ was added and the mixture extracted with EtOAc $(3 \times 30 \mathrm{~mL})$ and the combined organic layers washed successively with $10 \% \mathrm{NaHCO}_{3}$ and water, dried over $\mathrm{Na}_{2} \mathrm{SO}_{4}$, filtered, evaporated and chromatographed on silica-gel with mixtures of petroleum ether/EtOAc of increasing polarity $(19: 1 \rightarrow 6: 14)$ to give $2.20 \mathrm{~g}(28 \%)$ of $3,3.37 \mathrm{~g} \mathrm{(43 \% )}$ of 4 and $2.28 \mathrm{~g}(29 \%)$ of $\mathbf{3}+\mathbf{4}$ mixture, for a total yield of $7.85 \mathrm{~g}(78 \%)$. Compound 3: viscous oil; ${ }^{1} \mathrm{H}-\mathrm{NMR}: 5.39(1 \mathrm{H}, \mathrm{brt}, \mathrm{J}=6.9 \mathrm{~Hz}, \mathrm{H}-14), 4.98(1 \mathrm{H}$, ddt, $J=11.8,11.8,4.1 \mathrm{~Hz}, \mathrm{H}-2), 4.88$ (1H, s, H-17b), 4.56 (1H, s, H-17a), 4.02 (2H, dd, J=6.9, 4.2Hz,

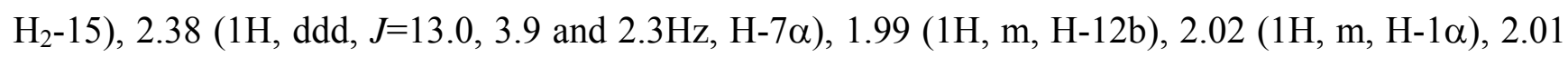


(3H, s, OAc), 1.99 (1H, m, H-12a), 1.93 (1H, ddd, J=13.0, 13.0 and 4.9Hz, H-7ß), $1.72(1 \mathrm{H}, \mathrm{m}, \mathrm{H}-3 \alpha)$, $1.70(3 \mathrm{H}, \mathrm{s}, \mathrm{Me}-16), 1.69$ (1H, m, H-6ß), 1.59 (1H, brd, $J=11.3 \mathrm{~Hz}, \mathrm{H}-9), 0.91$ (3H, s, Me-18), 0.86 (3H, s, Me-19), 0.73 (3H, s, Me-20); ${ }^{13} \mathrm{C}-\mathrm{NMR}: 43.9$ (C-1), 69.3 (C-2), 46.7 (C-3), 34.9 (C-4), 54.9 (C-5), 23.8 (C-6), 37.9 (C-7), 147.3 (C-8), 55.6 (C-9), 40.8 (C-10), 21.7 (C-11), 30.3 (C-12), 139.9 (C13), 124.7 (C-14), 58.9 (C-15), 23.3 (C-16), 107.4 (C-17), 33.5 (C-18), 22.4 (C-19), 15.2 (C-20), 170.6 $\left(\mathrm{CH}_{3} \underline{\mathrm{CO}}\right), 21.4\left(\mathrm{CH}_{3} \mathrm{CO}\right)$; IR: 3451, 3077, 2930, 1730, 1642, 1441, 1369, 1248, 1021; MS: $348\left([\mathrm{M}]^{+}\right.$ $<1 \%), 288$ (16.1\%), 273 (72.1\%), 225 (55.2\%), 202 (33.3\%), 175 (53.9\%), 135 (86.7\%), 121 (67.9\%), 55 (66.1\%), 41 (100\%). Compound 4, viscous oil; ${ }^{1} \mathrm{H}-\mathrm{NMR}: 5.37(1 \mathrm{H}, \mathrm{brt}, \mathrm{J}=6.8 \mathrm{~Hz}, \mathrm{H}-14), 5.00(1 \mathrm{H}$, ddt, $J=11.8,11.8$ and $4.1 \mathrm{~Hz}, \mathrm{H}-2), 4.86(1 \mathrm{H}, \mathrm{s}, \mathrm{H}-17 \mathrm{~b}), 4.53(1 \mathrm{H}, \mathrm{s}, \mathrm{H}-17 \mathrm{a}), 4.13\left(2 \mathrm{H}, \mathrm{d}, J=6.9 \mathrm{~Hz}, \mathrm{H}_{2^{-}}\right.$ 15), 2.38 (1H, ddd, $J=12.9,3.6$ and 2.2Hz, H-7 $\alpha), 2.14$ (1H, ddd, $J=14.0,10.4$ and 3.9Hz, H-12b), 2.04

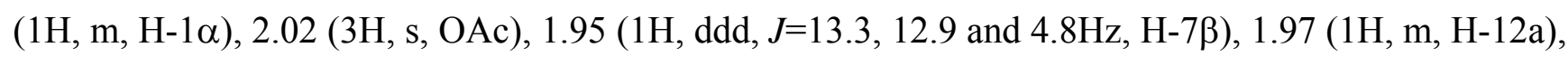
$1.72(1 \mathrm{H}, \mathrm{m}, \mathrm{H}-3 \alpha), 1.65$ (3H, s, Me-16), 1.69 (1H, m, H-6ß), 1.62 (1H, brd, J=11.1Hz, H-9), 0.92 (3H, s, Me-18), 0.87 (3H, s, Me-19), 0.75 (3H, s, Me-20); ${ }^{13} \mathrm{C}-\mathrm{NMR}: 44.1$ (C-1), 69.3 (C-2), 46.8 (C3), 34.9 (C-4), 54.9 (C-5), 23.8 (C-6), 37.9 (C-7), 147.3 (C-8), 56.2 (C-9), 40.9 (C-10), 22.0 (C-11), 38.3 (C-12), 140.1 (C-13), 123.2 (C-14), 59.3 (C-15), 16.3 (C-16), 107.3 (C-17), 33.5 (C-18), 22.4 (C19), 15.2 (C-20), $170.4\left(\mathrm{CH}_{3} \underline{\mathrm{CO}}\right), 21.3$ ( $\left.\mathrm{CH}_{3} \mathrm{CO}\right)$; IR: 3380, 3068, 2945, 1725, 1640, 1445, 1373, 1251, 1028; MS: 348 ([M] $\left.]^{+}<1 \%\right), 288$ (16.1\%), 273 (72.1\%), 255 (55.2\%), 187 (59.4\%), 175 (53.9\%), $135(86.7 \%), 121(67.9 \%), 41(100 \%)$.

Oxidative degradation of a 1a-2a mixture with the $\mathrm{OsO}_{4}-\mathrm{NaIO}_{4}$ system: synthesis of $2 \beta$-acetoxy-14,15,

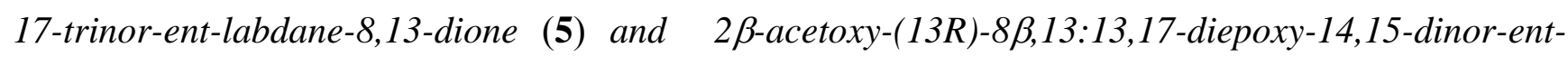
labdane (6)

Finely divided $\mathrm{NaIO}_{4}(3.1 \mathrm{~g}, 14.5 \mathrm{mmol})$, was added to a solution of 1a-2a mixture $(5 \mathrm{~g}, 14.45$ mmol) in 1:1 THF/ $\mathrm{H}_{2} \mathrm{O}(80 \mathrm{~mL})$ and the mixture stirred at room temperature under a $\mathrm{N}_{2}$ atmosphere. After $1 \mathrm{~h}, 4 \%$ aq. $\mathrm{OsO}_{4}$ solution $(5 \mathrm{~mL}, 0.787 \mathrm{mmol}$ ) was added. The reaction mixture was then stirred at room temperature for $72 \mathrm{~h}$, filtered and the solvent was removed until the volume was reduced to approximately $40 \mathrm{~mL}$; then $5 \% \mathrm{Na}_{2} \mathrm{~S}_{2} \mathrm{O}_{5}(15 \mathrm{~mL})$ was added, the mixture was extracted with EtOAc (3 x $30 \mathrm{~mL}$ ) and the combined organic layers were washed successively with $10 \% \mathrm{NaHCO}_{3}$ and water, dried over $\mathrm{Na}_{2} \mathrm{SO}_{4}$, filtered, evaporated and chromatographed eluting with mixtures of petroleum ether/EtOAc of increasing polarity $(19.8: 0.2 \rightarrow 5: 15)$ to give $3.16 \mathrm{~g}$ of compound $5(68 \%)$ and $0.335 \mathrm{~g}$ of 6 (7.2\%). Compound 5: viscous oil; $[\alpha]_{\mathrm{D}}{ }^{23}=+21.1^{\circ}\left(\mathrm{c} 1.2, \mathrm{CHCl}_{3}\right) ;{ }^{1} \mathrm{H}-\mathrm{NMR}: 4.93(1 \mathrm{H}, \mathrm{ddt}, J=12.1$, 12.1 and $4.0 \mathrm{~Hz}, \mathrm{H}-2), 2.56(1 \mathrm{H}$, ddd, $J=17.7,7.7$ and 5.4Hz, H-12b), 2.39 (1H, ddd, $J=13.6,4.6$ and $1.7 \mathrm{~Hz}, \mathrm{H}-7 \alpha), 2.26(1 \mathrm{H}, \mathrm{dd}, J=12.8,7.0 \mathrm{~Hz}, \mathrm{H}-7 \beta), 2.11(1 \mathrm{H}, \mathrm{brd}, J=10.7 \mathrm{~Hz}, \mathrm{H}-9), 2.05$ (3H, s, Me-

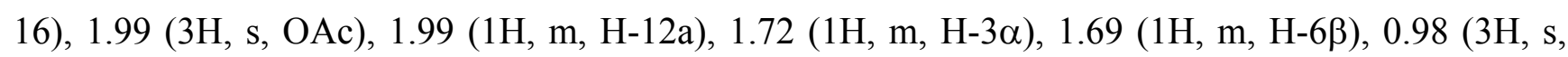
Me-18), 0.90 (3H, s, Me-19), 0.77 (3H, s, Me-20); ${ }^{13} \mathrm{C}$ NMR: 43.8 (C-1), 68.3 (C-2), 46.4 (C-3), 34.8 (C-4), 53.4 (C-5), 23.0 (C-6), 42.1 (C-7), 211.3 (C-8), 62.7 (C-9), 43.6 (C-10), 16.2 (C-11), 42.3 (C12), 208.9 (C-13), 29.8 (C-16), 33.5 (C-18), 22.3 (C-19), 15.3 (C-20), 170.4 ( $\left.\mathrm{CH}_{3} \underline{\mathrm{CO}}\right), 21.3$ ( $\left.\mathrm{CH}_{3} \mathrm{CO}\right)$. IR: 2950, 1738, 1723, 1721, 1429, 1368, 1245, 1189, 1025. MS: $322\left([\mathrm{M}]^{+}\right.$6.1\%), 249 (12.1\%), 247 (100\%), 189 (34.5\%), 180 (34.2\%), 177 (29.7\%), 135 (93.9\%), 119 (38.2\%), 43 (77.6\%). Compound

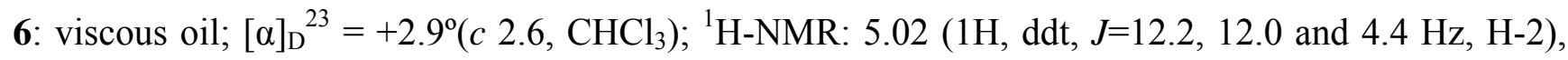

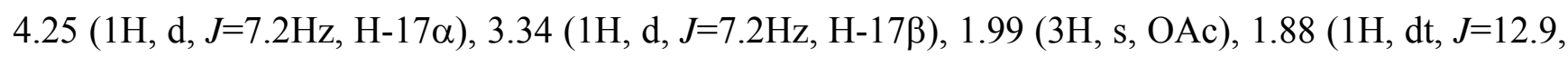


3.0Hz, H-12ß), 1.45 (1H, dd, J=11.7, 4.7Hz, H-9), 1.38 (3H, s, Me-16), 1.00 (1H, dd, J=15.6, 7.9 Hz, H-5), 0.95 (3H, s, Me-20), 0.93 (3H, s, Me-18), 0.87 (3H, s, Me-19); ${ }^{13} \mathrm{C}-\mathrm{NMR}: 43.8$ (C-1), 68.4 (C-2), 46.5 (C-3), 34.6 (C-4), 55.1 (C-5), 19.5 (C-6), 35.7 (C-7), 82.3 (C-8), 53.2 (C-9), 38.9 (C-10), 17.5 (C11), 35.9 (C-12), 106.1 (C-13), 24.1 (C-16), 73.4 (C-17), 33.6 (C-18), 22.4 (C-19), 15.5 (C-20), 170.5 $\left(\mathrm{CH}_{3} \underline{\mathrm{CO}}\right), 21.4$ ( $\left.\underline{\mathrm{CH}}_{3} \mathrm{CO}\right)$; IR: 2945, 1737, 1455, 1393, 1250, 1025; MS: $336\left([\mathrm{M}]^{+}<1 \%\right), 306(6.1 \%)$, 215 (13.9\%), 187 (41.5\%), 173 (33.9\%), 134 (27.3\%), 107 (24.2\%), $55(19.4 \%), 43(100 \%)$.

\section{Oxidative degradation of a 1a-2a mixture with the $\mathrm{RuCl}_{3}-\mathrm{NaIO}_{4}$ system}

To a solution of 1a-2a mixture $(5 \mathrm{~g}, 14.45 \mathrm{mmol})$ in $3: 4 \mathrm{CH}_{3} \mathrm{CN} / \mathrm{H}_{2} \mathrm{O}(70 \mathrm{~mL}) \mathrm{RuCl}_{3} \cdot 3 \mathrm{H}_{2} \mathrm{O}(50 \mathrm{mg})$ was added and the mixture stirred at room temperature. After $15 \mathrm{~min}$. finely divided $\mathrm{NaIO}_{4}(3.1 \mathrm{~g}, 14.5$ mmol) was added and the mixture was then stirred at $40^{\circ} \mathrm{C}$ for $5 \mathrm{~h}$. The mixture was filtered and the solvent was removed down to a volume to approximately $40 \mathrm{~mL}$, extracted with EtOAc $(3 \times 30 \mathrm{~mL})$ and the combined organic layers washed successively with water, dried over $\mathrm{Na}_{2} \mathrm{SO}_{4}$, filtered, evaporated and chromatographed eluting with mixtures of petroleum ether/EtOAc of increasing polarity $(19.8: 0.2 \rightarrow 6.4: 14.6)$ to give $3.53 \mathrm{~g}(76 \%)$ of 5 and $0.293 \mathrm{~g}(6.3 \%)$ of $\mathbf{6}$.

Oxidative degradation of a 3-4 mixture with the $\mathrm{KMnO}_{4}-\mathrm{MgSO}_{4}$ system: synthesis of $2 \beta$-acetoxy-14, 15-dinor-ent-labd-8(17)-en-13-one (7)

To a solution of 3-4 mixture $(2.28 \mathrm{~g}, 6.54 \mathrm{mmol})$ in acetone $(50 \mathrm{~mL})$, finely divided $\mathrm{KMnO}_{4}(1.03$ $\mathrm{g}, 6.54 \mathrm{mmol})$ and $\mathrm{MgSO}_{4}(0.785 \mathrm{~g}, 6.54 \mathrm{mmol})$ were added in small portions during 30 minutes and the mixture stirred at room temperature. After 72 hours, the mixture was filtered, evaporated and chromatographed with petroleum ether/EtOAc mixtures of increasing polarity $(19.8: 0.2 \rightarrow 15: 5)$ yielding $1.32 \mathrm{~g}(63 \%)$ of compound $7,0.181 \mathrm{~g}(8.6 \%)$ of compound 5 , and $0.025 \mathrm{~g}(1,2 \%)$ of compound 6. Compound 7: viscous oil; $[\alpha]_{\mathrm{D}}{ }^{23}=-17.6^{\circ}\left(c\right.$ 9.5, $\left.\mathrm{CHCl}_{3}\right) ;{ }^{1} \mathrm{H}-\mathrm{NMR}: 4.94(1 \mathrm{H}$, ddd, $\mathrm{J}=11.8,11.8$ and $4.1 \mathrm{~Hz}, \mathrm{H}-2), 4.79$ (1H, s, H-17b), 4.40 (1H, s, H-17a), 2.51 (1H, ddd, J=17.7, 8.8 and 4.6Hz, H-12b), 2.32 (1H, ddd, J=12.9, 3.9 and 2.3Hz, H-7 $\alpha$ ), 2.03 (3H, s, Me-16), 1.95 (3H, s, OAc), $1.88(1 \mathrm{H}, \mathrm{ddd}, \mathrm{J}=12.9,12.9$ and 4.9Hz, H-7ß), $1.57(1 \mathrm{H}, \mathrm{brd}, \mathrm{J}=11.6 \mathrm{~Hz}, \mathrm{H}-9), 1.99(1 \mathrm{H}, \mathrm{m}, \mathrm{H}-12 \mathrm{a})$, $1.72(1 \mathrm{H}, \mathrm{m}, \mathrm{H}-3 \alpha), 1.69$ (1H, m, H-63), 0.86 (3H, s, Me-18), 0.81 (3H, s, Me-19), 0.70 (3H, s, Me20); ${ }^{13} \mathrm{C}-\mathrm{NMR}: 43.8$ (C-1), 69.0 (C-2), 46.6 (C-3), 34.7 (C-4), 54.7 (C-5), 23.7 (C-6), 37.7 (C-7), 147.0 (C-8), 55.8 (C-9), 40.8 (C-10), 17.5 (C-11), 42.4 (C-12), 208.8 (C-13), 29.9 (C-16), 107.2 (C-17), 33.4 (C-18), 22.3 (C-19), 14.8 (C-20), 170.3 ( $\left.\mathrm{CH}_{3} \underline{\mathrm{CO}}\right), 21.3$ ( $\left.\mathrm{CH}_{3} \mathrm{CO}\right)$; IR: 3062, 2935, 1731, 1715, 1639, 1434, 1363, 1245, 1158, 1020; MS: $320\left([\mathrm{M}]^{+}<1 \%\right), 305(5.5 \%), 259(9.7 \%), 245(24.8 \%), 187$ (42.4\%), 135 (90.9\%), 121 (83.0\%), 119 (80.9\%), 107 (73.9\%), 93 (71.5\%), 79 (60.1\%), 43 (100\%).

\section{Acknowledgements}

The authors thank the Universidad Técnica Federico Santa María (grant DGIP $N^{\circ} 13.06 .26$ ) and Universidad Andrés Bello (grant DI-UNAB 13-04) for financial support. 


\section{References and Notes}

1. Martres, P.; Perfetti, P.; Zahara, J-P.; Weagell, B.; Giraudi, E.; Petrzilka, M. "A Short and Efficient Synthesis of (-)-Ambrox from (-)-Sclareol using a Ruthenium Oxide Catalyzed Key Step". Tetrahedron Lett. 1993, 34, 629-632.

2. Martres, P.; Perfetti, P.; Zahara, J-P.; Weagell, B. "Synthesis of Norambracetal: A New Ambergris Derivative". Tetrahedron Lett. 1993, 34, 3127-3128.

3. Barrero, A.; Alvarez-Manzaneda, J.; Altarejo, J.; Salido, S.; Ramos, J. M. "Synthesis of Ambrox from (-)-Sclareol and (+)-cis-abietol”. Tetrahedron 1993, 49, 10405-10412.

4. Ley, S. V.; Toogood, P. L. "Insect Antifeedants". Chem. Brit. 1990, 26, 31-35.

5. Anke, H.; Sterner, O. "Comparison of the Antimicrobial and Cytotoxic Activities of twenty Unsaturated Sesquiterpene Dialdehydes from Plants and Mushrooms”. Planta Med. 1991, 57, 344346.

6. Asakawa, Y.; Dawson, G. W.; Griffiths, D. C.; Lallemand, J. Y.; Ley, S. V.; Mori, K.; Mudd, A.; Pezechk-Leclaire, M.; Pickett, J. A.; Watanabe, H.; Woodcock, C. M.; Zhong-Ning, Z. “Activity of Drimane Antifeedants and Related Compounds Against Aphids, and Comparative Biological Effects and Chemical Reactivity of (-)- and (+)-polygodial". J. Chem. Ecol. 1988, 14, 1845-1855.

7. Butterworth, J. H.; Morgan, E. D. "Isolation of a Substance that Suppresses Feeding in Locusts”. J. Chem. Soc. Chem. Commun. 1968, 23-24.

8. Anderson, J. C.; Blaney, W. M.; Cole, M. D.; Fellons, L. L.; Ley, S. V.; Shephard, R. N.; Simmons, M. S. J. "The Structure of two new Clerodane Diterpenoid Potent Insect Antifeedants from Scutellaria woronowii (Juz); Jodrellin A \& B”. Tetrahedron Lett. 1989, 30, 4737-4740.

9. Kubo, I.; Lee, Y. W.; Pettei, M. J.; Pilkiewicz, F.; Nakanishi, K. "Potent Army Worm Antifeedants from the East African Warburgia Plants". J. Chem. Soc., Chem. Commun. 1976, 1013-1014.

10. Barnes, C. S.; Loder, J. W. "The Structure of Polygodial: A New Sesquiterpene Dialdehyde from Polygonum hydropiper L". Aust. J. Chem. 1962, 15, 322-327.

11. Jansen, B. J. M.; Groot, A. "The Synthesis of Drimane Sesquiterpenoinds". Nat. Prod. Rep. 1991, 8, 319-337.

12. Urones, J. G.; Marcos, I. S.; Gómez-Pérez, B.; Lithgow, A. M.; Díez, D.; Basabe, P.; Gómez, P. M. "Diastereoselective Ring-Opening of 12-Acetoxy-9 $\alpha$ and $9 \beta(11)$-Epoxy-7-Drimene: Homochiral Semisynthesis of Poligodial and Warburganal". Tetrahedron Lett. 1994, 35, 37813784.

13. Urones, J. G.; Marcos, I. S.; Gómez-Pérez, B.; Díez, D.; Lithgow, A. M.; Gómez, P. M.; Basabe, P.; Garrido, N. M. "Chemistry of Zamoranic Acid. Part V. Homochiral Semisynthesis of Active Drimanes: Pereniporin B, Polygodial and Warburganal”. Tetrahedron 1994, 50, 10995-11012.

14. Barrero, A. F.; Alvarez-Manzaneda, E. J.; Altarejos, J.; Ramos, J. M.; Salido, S. "Preferential Oxidation Reactions of the Side Chain of Unsaturated Labdanes”. Bull. Soc. Chim. Fr. 1993, 130, 700-707.

15. Vlad, P. F.; Koltsa, M. N.; Mironov, G. N. "Synthesis of Sesquiterpenoids of the Drimane Group from Labdane Diterpenoids". Russ. Chem. Bull. 1997, 46, 855-873. 
16. Rodilla, J. M. L.; Díez, D.; Urones, J. G.; Rocha, P. M. "From Labdanes to Drimanes. Degradation of the Side Chain of Dihydrozamorenic Acid." Molecules 2004, 9, 300-322.

17. Barrero, A. F.; Alvarez-Manzaneda, E. J.; Chahboun, R. "Enantiospecific Synthesis of (+)Puupehenone from (-)-Sclareol and Protocatechualdehyde". Tetrahedron Lett. 1997, 38, 23252328.

18. Barrero, A. F.; Alvarez-Manzaneda, E. J.; Herrador Mar, M.; Chahboun, R.; Galera, P. "Synthesis and Antitumoral Activities of Marine ent-Chromazonarol and Related Compounds". Bioorg. Med. Chem. Lett. 1999, 9, 2325-2328.

19. Del Corral, J. M ${ }^{\mathrm{a}}$. M.; Gordaliza, M.; Castro, Mª A.; Mahiques, Mª M.; Chamorro, P.; Molinari, A.; García-Grávalos, M". D.; Broughton, H. B.; San Feliciano, A. "New Selective Cytotoxic Diterpenylquinones and Diterpenylhydroquinones". J. Med. Chem. 2001, 44, 1257-1267.

20. Marticorena, C.; Quezada, M. "Catálogo de la Flora Vascular de Chile”. Gayana Bot. 1985, 42, 68-69.

21. Bohlmann, F.; Kramp, W.; Grenz, M.; Robinson, H.; King, R. M. "Diterpenes from Baccharis Species". Phytochemistry 1981, 20, 1907-1913.

22. Zdero, C.; Bohlmann, F.; King, R. M. "Ent-Labdanes, Manoyloxide and Helipterol Derivatives from Chrysocephalum Ambiguum". Phytochemistry 1992, 31, 1631-1638.

23. San Feliciano, A.; Medarde, M.; López, J. L.; Del Corral, J. M. M.; Puebla, P.; Barrero, A. F. “Terpenoids from Leaves of Juniperus Thurifera". Phytochemistry 1988, 27, 2241-2248.

24. Khac Manh, D. Do.; Fetizon, M. ; Flament, J. P. "Syntheses de Diterpenes Tetracycliques du Type Hibane". Tetrahedron 1975, 31, 1897-1902.

25. Leite, F, M-A.; Sarragiotto, M-H.; Imamura, P. M.; Marsaioli, A. J. “Absolute Configuration of Drim-9(11)-en-8-ol from Aspergillus Oryzae.” J. Org. Chem. 1986, 51, 5409-5410.

Sample Availability: Samples of compounds 1a-7 are available from authors.

(C) 2007 by MDPI (http://www.mdpi.org). Reproduction is permitted for noncommercial purposes. 